\title{
Too little, too late?
}

\author{
To win the fight against bird flu, the World Health Organization must forge partnerships with the governments of \\ developing countries hit hardest by the disease.
}

D eveloping nations such as Indonesia shoulder much of the world's bird flu burden, but do not have adequate resources to prevent its spread. The World Health Organization (WHO) has partnered with wealthier nations and funding agencies to provide aid, often in the form of supplies or technical support, to developing countries to fight bird flu. However, as two recent examples show, the WHO's actions don't make enough allowances for the socioeconomic and medical needs of these resource-poor countries. If we are to make headway against bird flu, this has to change.

\section{Vaccine development}

Under the current system of vaccine development, poor countries are unlikely to be able to afford vaccines developed from their own bird flu strains. The WHO collects virus samples from nations with infected individuals and freely distributes the virus samples to academic researchers and vaccine manufacturers worldwide. Once companies produce an effective vaccine, the vaccines are usually patented and sold at high prices. Clearly, this system is unfair to those countries that freely distribute their virus samples, yet are least able to afford the resultant vaccines.

A case in point is Indonesia, where more people have died from $\mathrm{H} 5 \mathrm{~N} 1$ infection than in any other country. The virus has claimed the lives of $70 \%$ of those infected. Although the reasons for the higher lethality are unclear, the strain's perceived toxicity has heightened its value in the eyes of vaccine manufacturers. But after learning that Australian company CSL had developed a bird flu vaccine using Indonesian virus without its permission, the Indonesian government decided on 7 February to sharply limit sharing of its viral isolates.

Because Indonesia continued to release sequence data on its virus strains, it still would have been possible to produce recombinant virus that could be useful for manufacturing vaccine. But recombinant viruses may not contain all of the pathogenic elements of the original viral isolate. Restricting access to the original strains would have significantly compromised the development of an effective bird flu vaccine.

Only after Indonesia's move to restrict access to their virus did the WHO take steps to address the inequalities inherent in the current system of vaccine development. The WHO promised to help Indonesia and other countries develop a homegrown vaccine industry so that their citizens would have direct access to affordable vaccines developed from their viral strains. The details of how or when the WHO will provide this assistance are unclear. Nevertheless, in return for the WHO's promise of aid, Indonesia has agreed to resume sharing its viral samples with the WHO.
In this particular case, the WHO managed to avert the crisis, but the organization should have taken steps to rectify these inequalities well before Indonesia's decision. A meeting is now being planned between the WHO and bird flu-afflicted countries to address how more equitable distribution of vaccines can be achieved-a response that is long overdue.

One clear step forward would be the establishment of public-private partnerships to ensure that funds are available to pay for new vaccines. A recent example of this is the Advance Market Commitment, launched by the governments of five nations as well as the Bill \& Melinda Gates Foundation. Together, the partners committed $\$ 1.5$ billion to pay for development of pneumococcal vaccines for children in developing nations. A similar partnership between vaccine developers and public and private funding bodies would speed development of bird flu vaccine, and allow access to the vaccine for developing countries that need it most.

\section{Protecting poultry}

Experts believe that most human cases of bird flu occur because of human exposure to infected domestic birds. Many of the infected lived in homes with backyard pens containing small flocks. Whenever an infected bird is discovered, the WHO calls for culling of all birds, whether infected or healthy, within a three-kilometer radius. However, this directive often is ignored by poultry farmers and rural households with small flocks because they depend on these birds for their livelihood. The governments of many countries have not instituted schemes to compensate these farmers for the loss of income from culling their birds.

What's more, the UN Food and Agriculture Organization and the World Organisation for Animal Health announced in April 2005 that culling is less effective than vaccination at preventing the spread of influenza among birds. But there is often insufficient vaccine for the number of birds that should receive it. In Indonesia in September 2005 , for example, 8 million birds needed to be vaccinated, but only 200,000 doses of vaccine were available.

Developing countries depend on the WHO and its financial partners in developed nations for aid in protecting their citizens from bird flu. But unless the WHO can ensure that its aid initiatives are backed up with financial, medicinal and human resources, it will be powerless to effect change. The WHO must collaborate with the governments, health agencies and agricultural industries of developing countries to come up with practical solutions now to eradicate bird flu—well in advance of a pandemic. Otherwise, help will arrive too late. 